\title{
Recodifications of academic positions and reiterations of desire: change but continuity in gendered subjectivities
}

Forthcoming in Studies in Higher Education, mid 2006 (page numbers not right...etc..)

\begin{abstract}
This paper argues that the analysis of changes in the social position of women needs to distinguish between levels of social practice and psychic subjectification. The argument draws on Lacan's conception of the relationship between subjectivity, desire and sexual difference to describe gendered aspects of subjectivity embedded within the (re)organisation of social fields. The data is taken from a comparative case study of undergraduate modules in four universities, and the analysis identifies gendered differences in the tutors' pedagogic and disciplinary practice. These differences suggest that while the practice of the female tutors, in different ways, constituted recodifications of existing disciplinary and pedagogic practices, these instances of recodification can simultaneously be interpreted as gendered identifications with an external, feminine position in relation to the dominant structures of the Symbolic Order. Thus, while change may be instituted at the level of practice within specific social fields, at the level of subjectification the recodifications that mark such changes can be read as a reiteration of primary gendered identifications.
\end{abstract}

\author{
Dr Claudia Lapping \\ Institute of Education \\ University of London \\ 20 Bedford Way \\ London WC1H OAL \\ Phone: 02076126342 \\ E-mail: c.lapping@ioe.ac.uk
}




\section{Recodifications of academic positions and reiterations of desire: change but continuity in gendered subjectivities}

\section{Introduction}

In this paper I am going to distinguish different levels of social practice and psychic subjectification within which it is possible to describe shifts in the regulation of gender. The more abstract level of my argument is that it is helpful to maintain a distinction between changes in the codes regulating practices within social fields and changes at the level of gender as a primary mark of human subjectivity within the Symbolic Order. At a more concrete level, I am arguing that while it is possible to identify gendered shifts in the codification of disciplinary and pedagogic practices within universities, the subjectivity of individual academics is still primarily embodied within the codes of hegemonic heterosexual gender identities. The description of these simultaneous levels of social regulation and psychic subjectification may contribute to existing analyses of the nature and extent of transformations in the position of women in contemporary society (for example, McNay, 2000, Skeggs, 2005). It may also help to shed light on the gendered nature of tensions in the pedagogic and disciplinary positioning of both women and men within the academy.

I am drawing on a piece of empirical research comparing literature and politics modules in contrasting institutions within the UK higher education system. Both disciplines and institutions were selected to represent contrasting positions in relation to social hierarchies. The study of politics is closely associated with the role of government, while contemporary literary studies tends to take a more explicitly politicised or critical position in relation to the existing social order. There is also a clear division in the higher education sector in the UK, with prestigious, selective institutions tending to recruit students from privileged social backgrounds, while the access oriented, ex-polytechnics tend to recruit more 'non-traditional' students. The sites that formed the empirical object of the research were American Literature and Political Thought modules on undergraduate degree courses. I observed two American Literature and two Political Thought modules, in two prestigious, highly selective universities (West University and North University) and in two 'new', access oriented universities (South University and East University). I participated in a series of at least six sessions on each of the four modules. I videoed the sessions and interviewed students and tutors about the discussions that I had observed.

The main object of the research was to identify the effects of contrasting disciplinary and institutional settings on the positioning of students within class discussions, with gender as a central organising principle within the analysis. Thus, in my initial conceptualisation of the research I was trying to capture the relational effects of gender, discipline and institution on student subject positions. However, during the analysis these same relational effects also emerged in relation to the four class tutors. I am explaining the slight marginality of the analysis of tutor positions within the initial design of the research project because despite my clear conceptualisation of gender as a central criterion for analysis within the study, I was oddly disconcerted, and saddened, by the emergence of a strong conformity with codes of gender in the classroom practice of the tutors. This may merely signify my own naïvity, but, for me, it also reaffirmed an empirical basis for my gendered interpretations. When I was analysing student positions, to some extent at least, I only found what I was already looking for. In contrast, the emergence of gendered patterns in my analysis of the academic practice of the tutors was something I had not anticipated. It is the analysis of tutor positions in relation to both disciplinary and pedagogic cultures that I am going to present in this paper. 
My argument is that while at one level of analysis it is possible to interpret the practice of female university tutors as re-codifying disciplinary and pedagogic cultures within the university, at the same time it is also possible to identify ways in which these very acts of recodification reiterate the external position of the feminine in relation to the structures of the Symbolic Order. Before engaging with the data, I want to explain the framework I am using for conceptualising gender, using the association Lacan introduces between feminine positions and his conception of desire.

\section{Feminine jouissance as an exemplar of unarticulated desire}

Lacan is very precise about the meaning of 'desire'. His concept can only be properly understood within his broader conceptual structure of the Real, that which is beyond language or knowledge, the Imaginary, the idealised, unified relationship between two subjects, and the Symbolic Order, the linguistic and social regulations the subject enters into through the introduction of a third term, the Father, into the idealised, Imaginary relationship between mother and child. Within this structure, need, or appetite is situated in the Real. This appetite can only be articulated within language, as a demand, but since there is always a gap between the language of the Symbolic Order and the Real, the demand can never express the appetites of the Real: 'Demand in itself bears on something other than the satisfaction it calls for'(Lacan, 2001, p. 317). There is, then, a gap, or a remnant, between appetite and demand, and this gap is the position of desire:

Thus desire is neither the appetite for satisfaction, nor the demand for love, but the difference that results from the subtraction of the first from the second, the phenomenon of their splitting. (Lacan, 2001, p. 318)

This splitting, between the subject and their desire, between the possibility of fulfilment and representation within language, produces the divided subject of the Symbolic Order. The concept of a divided or incomplete identity, subject of a continuous making and remaking within discourse, is familiar within 'structuralist' and 'post-structuralist' sociology. The relationship between the divided subject, desire and sexual difference that is also inherent to the Lacanian concept, is less well rehearsed within sociological literature.

The conceptual relationship between the divided subject, desire and sexual difference is based on clinical observations within psychoanalytic settings. Although the context of clinical analysis is very different from that of sociology, it is important to note this empirical derivation, which acts both to validate and also to limit the disciplinary re-contextualisation of psychoanalytic terms. Sociology cannot reproduce the methods of the analytic relationship: it can, however, translate insights produced through these methods to help to make sense of sociological data ${ }^{1}$.

The clinical data that provide a basis for the association between sexual difference, subjectivity and desire as a remnant outside language, are derived from the analysis of resistance in hysterical patients. Paul Verhaeghe sites the 'discovery' of this association in Freud's recognition of the failure of his treatment of his hysterical patients (Verhaeghe, 1999). Freud's initial expectation had been that the process of identifying and revealing the resistance to the patient would itself constitute a cure. Yet with many of his patients (see also Appignanesi and Forrester, 2005), Freud's revelations were rejected:

\footnotetext{
${ }^{1}$ Sociology and psychoanalysis are activities carried out in distinct professional contexts and deploying methods specialised to those contexts. The application of concepts derived from one setting to describe the practices of the other is, therefore, a colonisation that recontextualises the colonised activity and transforms the colonising language. For a fuller elaboration of recontextualising strategies, see Dowling, 2005, 1998.
} 
Hysterical patients didn't want to know anything about Freud's cure. He was convinced he could bring them the Freude, the ability to have pleasure, but they refused. ... (Verhaeghe, 1999, p. 130)

Freud's patients' refusal to accept his interpretations, according to Verhaeghe, led to his reconceptualisation of resistance, desire and the nature of the unconscious. These developments, Verhaeghe suggests, in turn lead to the Lacanian redefinition of the relationship between the subject and desire. Whereas in earlier Freudian theory it was assumed that the subject sought the satisfaction of desire, Freud's revelation suggested that the subject may have some investment in the maintenance of unsatisfied desire: that the remnant that resists symbolisation is intricately connected with human subjectivity.

My interest is in the way these ideas are related to a conception of sexual difference, and, ultimately, in how they can help us to understand the persistence of the fundamental sexual division despite significant changes in social codes regulating both masculinities and femininities. One way to understand the persistence of sexual division, I believe, is through the association between the feminine position and the concepts of jouissance and desire.

Jouissance, literally 'orgasm', represents an Imaginary completeness, an overwhelming satisfaction of subjective desire that cannot be symbolised within language. Feminine jouissance is often taken as the exemplar of unarticulated desire, and thus forms a link between the social order, sexual difference and human subjectivity ${ }^{2}$. The initial basis for this link was observations made within clinical practice. Verhaeghe cites an example which can help us to understand the relationship between feminine jouissance and a Lacanian conception of desire:

\begin{abstract}
A young hysterical woman suffers from frigidity, and the analyst-novice tries as hard as he can to make the analysis into a success, which is, from his point of view, to enable her to enjoy orgasms. And - miracle of miracles! - the treatment works: "Yesterday, I made love to my husband and I experienced an orgasm." The analyst is in seventh heaven, marvelling at his own qualities as a therapist, until his patient wakes him from his rosy dream: “ My husband made me come, but now I definitely don't want to make love to him anymore.” (Verhaghe, op. cit. p. 131)
\end{abstract}

The obvious point made here is that the analyst has misunderstood his patient's desire, or, in Lacanian terms, he has misunderstood the nature of desire, since desire always resists interpretation. The broader point that the example can be used to support is that female jouissance, women's sexual desire, is not represented within the language of the Symbolic Order. This second point requires further explanation.

The question of what is or is not represented within language is dependent on the question of who controls language and the production of knowledge. Lacan makes this point, citing women patients' apparent lack of knowledge of their own jouissance, and the way a language to describe women's experience has been produced by anybody but the women themselves:

The plausibility of what I am claiming here - namely, that woman knows nothing of this jouissance - is underscored by the fact that all the time people have been begging them, begging them on their hands and knees - I spoke last time of women psychoanalysts - to try to tell us, not a word! We've never been able to get anything out of them. So we call this jouissance by whatever name we can come up

\footnotetext{
${ }^{2}$ This link between gender and subjectivity has been criticised by some feminist theorists as both universalising and essentialising existing gender divisions ( Butler, 1993, 2000, Fuss, 1989). I am not going to explore these criticisms directly here. Persuasive arguments that these readings misrepresent Lacan's ideas have been presented by numerous theorists (Lacalu, 2000, Ragland Sullivan, 1986, Rose, 1986, Zizek, 1994).
} 
with, "vaginal," and speak of the posterior pole of the uterine orifice and other such "cunt-torsions" (conneries) - that's the word for it! If she simply experienced it and knew nothing about it, that would allow us to cast myriad doubts on this notorious (fameuse) frigidity. (Lacan, 1988, p. 75)

Lacan's suggestion that in the end 'we' have to label what women refuse to name - 'we call this jouissance by whatever name we can come up with' - echoes Virginia Woolf's ironic question, as she is reading the British Library catalogue of male writing listed under the subject heading 'women': 'Why does Samuel Butler say, "Wise men never say what they think of women"? Wise men never say anything else apparently' (Woolf, 1994, p. 34). Lacan, too, is questioning why men, or psychoanalysts, rather than women themselves, are left to define what 'woman' means. The evidence of the inability of women patients in analysis to express or accept sexual fulfilment is simply an example of the way in which the codes of the Symbolic Order exclude 'woman' from the possibility of becoming a whole subject. Although all human subjects are necessarily divided within language, the Symbolic Order provides signifiers that more closely represent masculine desire as a coherent gendered identity. It is not the case that jouissance is essentially unavailable to any form of symbolic representation, but the dominant codes of a patriarchal social order have not allowed women to control the representation of their desire.

It is useful to think a little more about Lacan's choice of women's jouissance to exemplify his description of that which is excluded from language. In choosing jouissance as the defining instance of desire, Lacan foregrounds the central function of gender in our production of ourselves as (sexed) subjects. The strength of resistance, discovered in the clinical setting, to articulating aspects of desire can be explained by reference to the primacy of gender as a mark of subjectivity: since it is impossible to be a subject without at the same time being a sexed subject, the codes regulating the practice of gender wield excessive power. The picture Lacan presents of female patients' unwillingness or inability to describe their own experience is still relevant, and is plausible as a description of many aspects of women's lives today. My analysis of the practice of male and female tutors suggests that women academics exhibit a similar reticence in expressing desired disciplinary identifications. The fact that women's desire, whether purely sexual or otherwise, should be so hidden, ignored or repressed suggests that conformity to codes of acceptably gendered practices is in some way necessary to a stable female subjectivity. Lacanian theory suggests that while masculinity is reinforced through identifications with dominant discourses, feminine sexuality, the meaning of 'woman', exists outside dominant structures (Lacan, 2001, 1988). The lack of knowledge of female jouissance and women's inability to name their desire represent, simultaneously, both production of and conformity with the historically specific codes of the Symbolic Order. Transgressing these codes incurs a loss of femininity, and therefore puts at risk a stable position as a gendered social subject.

The argument that I want to make here is that there is an important distinction between changes in codes within specific social fields, such as the university, and the far less flexible code regulating identification as a gendered subject within the Symbolic Order. The embedded practice of individual subjects necessarily engages with both of these levels of regulation.

\section{Recodifications of pedagogic relations in Political Thought classes}

There were significant similarities in the presentation of Political Thought in South and West Universities. The canon of modern Political Thought is narrow and extremely stable, and as a result the course outline and set texts for the observed modules were very similar. The 
courses presented canonical positions within liberalism, social liberalism, social contract theory and Marxism, and most of the lecturers I talked to found it relatively unproblematic to identify their position within these categories.

There were, however, clear contrasts between the pedagogic approaches adopted in the two universities. West University put a strong emphasis on student participation in seminars: there was even a rumour that class tutors were explicitly directed not to intervene to fill silences if students didn't respond to a question. The rumour might have been a little extreme, but the ethos behind it was confirmed by the course co-ordinator:

Cheryl: Some teachers are more proactive than others. I have one teacher in particular who, if there is a blank in the discussion, is more than fearless, really. But the ideal class is one where the teacher says very little and where the students do the work. (Cheryl, interview)

Cheryl's account of one teacher as 'more than fearless', which appears to be a reference to their ability to sit out uncomfortable silences, re-iterates a fairly common conception of students as equal, or even threatening opponents to their teachers (see for example Mirfield, 2001, pp. 38 - 39). Within West University this conception of the student as able to contribute, expected to contribute and, perhaps, in a position of strength when they fail or refuse to speak in class, appears to have been embedded within understandings of good teaching practice. There were advantages to this approach, in particular the way it correlated with high expectations of students in terms of reading and understanding. In contrast, the South University tutors had relatively low expectations of students in relation to both the completion of weekly reading and contributions to class discussions. Tutors from various departments talked about a 'decline in the reading culture', and this correlated with a perception that students want to be 'taught by the teacher'. These two factors were consistent with a culture within which fewer students made interventions within sessions and tutors took a far more didactic approach than in West University.

The first example I am going to discuss reveals how the teaching style of Alison, a postgraduate student teaching an undergraduate Political Thought seminar in West University, constitutes a subtle recoding of the assumptions behind the preferred pedagogic practices of the institution. At the same time, though, her practice can be read as a refusal to identify fully with existing pedagogic and disciplinary structures and as a reiteration of an external, feminine position.

Alison's style in the Political Theory seminars that I observed was consistent with the institutional ideal articulated by Cheryl in that she spoke relatively little and her students, or, certain students within the group, spoke a lot. Her teaching style might, then, be explained in part by the institutional culture. Another possible factor that may have facilitated student participation was the fact that Alison was a post-graduate student, and not the course lecturer. It is certainly the case that the students did not feel intimidated by her: the more vocal male students interrupted and contradicted her frequently in the seminars and the quieter female students that I interviewed all commented on how well she had managed to facilitate their participation. This level of student participation can be related to specific methods Alison used in the classroom: she asked questions to elicit students' views, she encouraged students to respond directly to each other's points, and she explicitly asked for the opinions of quieter students.

Alison herself provided a more personal rationale for this approach. She produced the following account in response to, or perhaps in explanation of, an extract from the transcript 
of a fairly typical, unfocussed section of class discussion where students had been expressing views on whether people are essentially group oriented or whether they are essentially individual, only gathering together to further individual interests:

Alison: (...) In so far as they have been talking about what drives political communities, it's an issue that's very important (...) I don't think they will get it now, but hopefully later, as long as they think about it. I really am interested in getting people to think about certain issues. Sometimes the spelling out can be too much. If I just went there and said 'you mean this and this'. I don't want them to feel that they're being put in a box, I don't want them to feel 'this is where I stand'. Yes, once you're past a certain level you can do that. You can align yourself with this and that positions, but what I really want them to do, on this course, is to think about issues. To see that there are issues, and to see that they can deal with them, would be more important for me than saying 'I'm a liberal', 'I'm a communitarian' (...) to come out understanding the things we're looking at rather than categorising them.

(Alison, West University tutor, interview, p. 5 - 6)

There are two aspects to Alison's account here. Firstly, she prioritises developing students' sense of real conceptual controversies over the precise detail of specific arguments and positions: 'I am really interested in getting people to think about certain issues. Sometimes the spelling out can be too much.'. This relates to the second aspect, which is her suggestion that she wants the students to develop their own response to each issue before they begin to identify with generalised categories such as 'liberal', or 'communitarian'. Both of these aspects of her account can be related to her own academic position and educational experience. She described her discomfort with the need to take up a position in her thesis:

Alison: My position is quite unclear ... the position I take in my thesis is probably quite different to what I take as a person. The position I take in my thesis is quite left wing, I would say: egalitarian, liberal egalitarian, residual Marxist. Purely pragmatic so I can get it out of the way ...

(Alison, West University tutor, interview)

This sense of conforming to disciplinary conventions rather than expressing her own ideas is also evident in her description of her previous educational experience as 'stifling', which influenced her student-centred approach and her interest in eliciting students' own opinions:

Alison: In their discussions there is a balancing act between not letting things go completely off and on the other hand not stifling them when they're eighteen, when they are still very eager and they're curious. And my personal experience has been of being stifled, and so maybe I tend to let them go on because I think, okay, practice in saying something, practice in just communicating to others what you think, because sometimes that's harder than stringing together logical sentences, is to make yourself understood. (Alison, West University tutor, interview)

This sense of being 'stifled' might be considered surprising in the light of the fact that Alison herself comes from an academic family, and so might be expected to feel comfortable in an academic context. However, Alison's experience can also be related to issues of gender. When I asked her about gender in the classroom, she said she had never really thought about it, because she automatically accepted that she would be 'downgraded' because of being a woman:

Alison: Perhaps I'm more oblivious to the gender issues, perhaps also because I'm used to, from my upbringing in India and also from my continental upbringing, already you just feel downgraded as a woman anyway. So my expectations are probably extremely low.

(Alison, West University tutor, interview)

Alison's strong sense of having been stifled both in her academic and in her educational experience contributed to her developing a teaching style that allowed students to express 
their ideas in a way which conformed to the pedagogic ideal set out by the department. It might almost be argued that she was allowing the 'stifling' she experienced as a student to be re-enacted upon her by her (male) students, when they interrupted and contradicted her. Her account of her teaching might be read as constructing an extremely coherent rationale for reoccupying this highly feminised position.

However, in providing this rationale, which prioritises student participation, not as a test of their abilities, but rather as a way of helping them to develop the skills and confidence to express their ideas, she is also re-codifying pedagogic practice within her university. This recodification was largely implicit, enacted within Alison's classroom, where quieter students - students who said that they rarely or never spoke in their other classes - were sensitively encouraged to contribute. However, Alison's practice also influenced the more explicit, written codes for student participation. Seminar tutors were required to complete a departmental report form on each student in their groups, which included a section evaluating their classroom participation. At the beginning of the module, Alison had explained this to her students, and suggested that any student who felt uncomfortable speaking in class could let her know, so they would not be marked down for a lack of contribution. She reported that several students had come to speak to her in this way, and she had been able to support them, both by explaining their reluctance to contribute on the report, and also by taking care to include them where possible in the class discussions.

What I am suggesting in this analysis is that Alison's presence as a tutor in West University did indeed recodify the practices of the institution, but, at the same time, at a more subjective or personal level, it can be suggested that she was reoccupying an external, feminine position through her failure to identify with dominant disciplinary structures in either her academic writing or in her classroom practice. A comparison with the male Political Theory tutor in my study, who did not appear to challenge either disciplinary or pedagogic conventions within his classes, may help to clarify the nature of Alison's practice.

Bill, the South University Political Thought lecturer, was almost the exact inverse of Alison in teaching style, in academic position, and in educational experience. He was from a working class family, but went to a competitive grammar school, where he did A-levels early and then spent a further year in the sixth form preparing for his first year at Oxford. So by the time he arrived there he was already partially inducted into Oxford's elite academic culture. In addition, he was also already confident of his Marxist politics, and in support of this his college at Oxford arranged for him to take several of his courses with Marxist academics from other colleges. In discussion of his teaching he articulated an explicit commitment to principles of educational equity. However, his active political work was generally directed at the level of national policy rather than at the level of the classroom. Unlike Alison, Bill had a clear sense of boundaries for legitimate discussion in the classroom, and was uncomfortable when the discussion moved away from the academic agenda. Bill's teaching style was also significantly different from Alison's. The pattern of seminars was for Bill to ask for questions or comments. When comments or questions were offered, he would respond, frequently at some length, expecting students to argue their point, rather than first eliciting more about what they might be trying to say. He did not, in contrast to the other tutors I observed, direct questions at the students. Whereas in Alison's class, there was constant direct interaction and discussion between students, this type of general discussion only occurred twice during the sessions that I observed at South University, and on each occasion Bill fairly quickly drew the discussion to a close, returning to his own exposition of the set author. 
In his interview Bill explained his discomfort with allowing students free rein to discuss ideas among themselves. He described the dilemmas he had faced when students had briefly engaged in a discussion of this type during the session on Marx:

Bill: This is a very confused debate. I remember it actually. It didn't focus in on arguments, or rather, it was about people's gut assumptions about politics. (...) That was where I deliberately sat back, because I could see it was chaotic and I wanted to let it go for a bit. Also because, being a Marx person, I was worried about taking it over completely (...) I think you have to allow that space to happen, because if people are thinking in chaotic ways they have to have the opportunity for that to emerge. I think what I tried to do here was to allow people space, and then come in with a long and heavy bit, probably much too long, looking at this.( ...) I'm letting it go, because people are actually cutting in and engaging, even if they're doing it in this rather chaotic way. And they're using the space for something in a way that it's not supposed to be for, but in a way it's not a bad thing, that is, to start saying something about their own ideas about politics. And they're very chaotic ideas ...

(Bill, South University tutor, interview)

Bill's dilemma was whether and how long to allow the discussion to continue, since it was 'using the space for something ... that it's not supposed to be for'. While he did seem to value the fact that 'people are actually cutting in and engaging', he did not, unlike Alison, have a clear rationale for valuing this participation regardless of the actual content of the interventions. His inclination, as he himself recognised, was to 'come in with a long and heavy bit'.

As both an academic and a political activist, Bill identified with the subject position of an authorised speaker in relation to the discipline of political thought on several significant levels. Perhaps, in part, it was this strong disciplinary identification that made it difficult for him to sit back and let students take control of the discussion. His mode of participation, it could be argued, was very similar to that of some of the male students in Alison's elite West University class and can be related to the culture of Political Thought, within which the expression and defence of your own position is the dominant mode of engagement with the discipline (see Lapping 2004, 2005). This is a mode of participation that represents very closely both the authorised subject position of Political Thought and also the dominant pedagogic culture of South University, and as such, does not challenge or reshape existing codifications of academic practice.

The suggestion I am making is that this coincidence of disciplinary and pedagogic practices is also related to gendered aspects of subjectivity, which, for men, are constituted through a close identification with dominant discourses. For women, in contrast, too close an identification with dominant discursive positions can destabilise their performance of femininity. Thus although Alison expresses uncertainty about her disciplinary position and a sense of being stifled within her education, these symptoms of marginalisation in relation to academic practices simultaneously reiterate her identification with the feminine position and thus reinforce the gendered nature of her subjective identity. She is, perhaps, similar to the patient who said "My husband made me come, but now I definitely don't want to make love to him anymore." As a PhD student she might appear to desire identification with academic discourse, but this identification would threaten her femininity, which can only be maintained by avoiding the fulfilment of this apparent desire.

\section{Recodifications of disciplinary boundaries in American Literature classes}

The American Literature modules observed in the study both conformed to the multimethodological approach prevalent in contemporary literary studies. This approach incorporates historicist, Marxist and feminist readings and readings that prioritise issues of 
ethnicity and racism. These readings draw on sociological, psychoanalytic and political theory as well as the more traditional literary approaches of New Criticism and close textual analysis. I have also argued (Lapping, 2004) that the culture of literary studies and its prioritisation of reading and close textual analysis contributed to similarities in the pedagogic approaches observed in the two classes: students and tutors in both universities shared a clear expectations that set reading would be completed before seminars; both tutors designed classroom activities based on analysis of selected extracts of text; and the interpretive nature of the discipline, which supports multiple legitimate interpretations, meant that student contributions were rarely disputed or 'corrected' by either the tutor or other students.

However, despite these similarities, there were significant differences in the ways in which the two American Literature tutors both conceptualised the boundaries of the discipline and constructed their positions as academic/tutor. Hannah, the tutor at East University, did not construct a very definite boundary between the discipline of American Literature and the personal and political experiences of the students. She also varied her position in classroom interactions, moving from the highly academic to the more personal, and at times took a relatively light hearted, un-academic approach to what was being said in the sessions. Duncan, in contrast, had an explicit conception of the boundary between the academic and the personal and maintained a rigorous academic position throughout the sessions. These differences are consistent with the definition of the masculine position situated in identification with, and the feminine position as on the outside of dominant, in this case academic, discourses.

In explaining the purpose of the classes Hannah talked about the overlap between issues addressed in the literature and issues relevant to students' lives. She suggested that the purpose of the taught sessions was to excite students' interest in the subject, and to do this, she said, it was important to demonstrate how the texts are relevant to the students' experience. She felt it was both obvious and useful for students to refer to personal issues and to their own sense of their gendered, ethnic, or class identity and concluded, 'I think that very often you can have good seminars when people talk about themselves in that kind of way'.

Reflecting this approach, there were several instances in the observed sessions where Hannah explicitly invited students to reflect on their personal experience. In at least one instance, this led away from a direct focus on the set text, while one student speculated about the relationship between his gendered and ethnic identities. When she explained how she felt about this extract, Hannah suggested that it had raised interesting issues that were not directly related to the text, but which she would have liked to follow up:

That conversation left me, I thought it was quite problematic because I wondered whether the fact that I think of myself primarily as a female rather than primarily as white is to do with issues of race, you know. I don't have to think about my whiteness because it's the invisible colour, whereas if I was black I'd have to think about it. And maybe we should have had a discussion about that, because I did feel at the time that it was quite unsatisfactory. But I didn't want to, I suppose I didn't want it to go off at a tangent. (Hannah, East University tutor, interview)

Although her sense of a boundary meant that she 'didn't want it to go off at a tangent', it is clear that Hannah felt that the issues raised in the class were legitimate material for academic discussion.

While the introduction of personal and political issues into literary studies is, clearly, not specific to Hannah, the recodification of the discipline that has taken place in recent years can 
be attributed, at least in part, to the expansion of the academy to include more practitioners from groups who have traditionally been underrepresented within higher education. Feminist academics, and perhaps women academics in general, can make a persuasive claim to have had a significant influence on recent developments in both literary and cultural studies and also in sociology. Thus, at one level at least, Hannah's conception of disciplinary boundaries can be seen as contributing to a more general shift in the codification of literary studies.

Duncan, the North University American Literature tutor, expressed slightly different feelings about the introduction of personal issues into his teaching sessions. In the interview, we discussed an extract from a session on slave narratives where a female student, Razia, had talked about the way she responded to different representations of women's lives. She had suggested that her ability to identify with women characters was dependent on the extent to which she shared their emotions and experiences. She compared her experience of reading Toni Morrison's novel Beloved to her experience of reading Harriet Jacobs' autobiographical narrative, Incidents in the Life of a Slave Girl, suggesting that she found the narrative easier to read because it downplayed the violence Jacobs had suffered under slavery. In her narrative, Jacobs describes how her master made advances to her, but does not depict an actual rape. Several students in the class questioned how convincing this was, and Razia had responded to this suggestion:

Razia: When I read it, I just took it that he hadn't raped her. But now, speaking about it, and also other texts that I've read about the time, not autobiographies, just texts written about slavery, like Beloved, it was more prominent. Rape was much more prominent in it. In this one it was more like a personal journey through slavery, and I found it easier to relate to, because sometimes, texts about slavery can be really shocking, and even though you sympathise with people, because what's happened to them is so awful, it's so far removed from what you've experienced yourself. Whereas I found it easier to read her text [the Jacobs]. It was just a woman going through life and there were like emotional things involved.

(North University, Slave Narratives)

Duncan's response when we looked at this extract in his interview was slightly negative:

Towards the end of the extract it becomes a bit un-textually grounded, not un-textually grounded, but the level of analysis is quite sort of shallow, perhaps, or basic, 'I found this really shocking', 'it was how I related to it as a sort of person in my contemporary space' - all that stuff that's sort of quite A levelly. But I think, I don't mind that happening occasionally in classes, because I think those are the ways you respond to a text and you do have to acknowledge that (...) I do want to sort of push those buttons in people. I wouldn't want this sort of thing to appear in a student's essay, but there is a place for that in class. (Duncan, North University tutor, interview)

While he acknowledges that 'there is a place for that in class', Duncan suggests that Razia's reference to her personal experience is 'shallow', 'basic', and 'quite A levelly'. He is constructing a clear distinction between legitimate and illegitimate modes of analysis, and explicit reference to the personal appears, for him, to be illegitimate.

The contrast between the tutors affects their positioning in relation to a certain conception of what it means to be academic. Duncan's seriousness during the classes, his discomfort with what he sees as un-academic contributions from students and his consistent use of a precise and rigorous academic language, constituted a strong identification between him and a formal conception of academic modes of thinking. Hannah, in contrast, explicitly distanced herself from this position through the use of informal language, through the interjection of offhand comments during the seminars and through references to personal issues. Duncan expressed concern about an incident where he hadn't remembered a detail about a text during a seminar, 
saying, 'what I remember about that was not being quite in control'. In contrast, Hannah expressed less concern about such losses of control, saying, 'I admit to not knowing things all the time.' It would be possible to suggest that both in her academic interests and in her interaction as a teacher, Hannah values the personal and is relatively comfortable relinquishing control, while Duncan is sceptical of the value of the personal in academic work and is uncomfortable relinquishing control. However, an analysis more in line with a Lacanian conception of the feminine can provide a less individualising account. It is possible to align the ability to identify fully with academic discourse with the masculine ability to express sexual desire. Just as female analysands have to deny knowledge of their own jouissance in order to maintain their gender position, so, perhaps, female academics have to disguise their own seriousness in their intellectual pursuits. Academic work, like sex, within this conceptual framework can be described as the embodiment of the masculine position, not, of course, because women are inherently less capable of, or derive less pleasure from either activity, but because conformity with socially imperative codes of femininity requires the repression of such pleasures.

\section{Conclusions: social regulation and subjective identification}

The subjective positions of both male and female tutors in the study are more complex than, perhaps, my argument has suggested. The male tutors appeared more concerned with the maintenance of disciplinary boundaries, which supported an identification with dominant, masculine discursive positions. But this identification with a position of mastery is neither complete nor satisfactory: it is a powerful regulative demand on the subject that Stephen Frosh has described as 'both deathly and creative' (Frosh, 1994, p. 74). Frosh points out that " "having' the phallus attached to oneself is no guarantee of stability of identity; quite the contrary, it forces the man into an obsession with 'getting things straight' and a terror of loss which must seem comic to the penis-free woman" (ibid, p. 77). Free of this 'terror', both female tutors in the study, in different ways, disrupted disciplinary boundaries and distanced themselves from too close an identification with academic discourse. Thus, I have argued, their presence within the academy necessarily instituted re-codifications of existing disciplinary and pedagogic discourses, while simultaneously reiterating a feminine desire that is positioned outside the dominant structures of the Symbolic Order.

This analysis does not foreclose possibilities for change, but foregrounds the persistence of sexual difference as a primary organising principle of social relations, as well as the symbolic and psychic dangers of transgressing codifications of sexual division. Psychoanalytically informed feminist theory struggles to find a political strategy that destabilises gender hierarchies, but that does not embrace an impossible outside of language and the law (Butler, 1993, 2000, Rose, 1986, Kristeva, 1986a, 1986b). Luce Irigaray and Lois McNay both criticise Lacanian approaches as leaving no space between language, subjectivity and the social. Both, in quite different ways, reconceptualise the disjunctures between sensuous, bodily experience and the symbolic realm as a more radical, creative 'imaginary', offering possibilities for a positive reconfiguration of gender (McNay, 2000, Irigaray, 1985, 1993, Whitford, 1991). Kristeva's conceptualisation of the 'semiotic' is also sometimes presented in this way, as a potential strategic space for the radical subversion of linguistic structures.

It might, then, be possible to construct an interpretation of the practice of female tutors as a destabilising transgression of phallocentric institutional structures. The reiteration of the feminine within pedagogic relations can be interpreted as radically shifting the relationship between students, tutor, and institutionalised knowledge. But the effects of these agentic or transgressive moments are unpredictable (see Frosh, 1994, ch. 6, Butler, 1993, 2000), and the 
stability of such re-codifications depends on a range of contextual factors. Alison's position as a post-graduate student may restrict the sustainability of any changes to pedagogic practice she may have initiated within her institution. Recodifications articulated from Hannah's position of relative institutional authority may prove more sustainable. There is, though, also evidence that disciplinary re-codifications are often unstable or marginalised within the academy $^{3}$. Alternatively, as Kristeva has suggested, such radical moments may be neutralised when they are taken up and absorbed into professional practice (Kristeva, 1986b).

My argument is that these simultaneous effects of change but continuity can be better understood if read as acting at the different levels of social practice and psychic subjectification. While change may be instituted at the level of practice within specific social fields, the fields of disciplinary or pedagogic practice, for example, my analysis suggests that at the level of subjectification the recodifications that mark such changes can also be read as a reiteration of primary gendered identifications. Change can thus take place within specific social fields while the fundamental gender division, primary mark of subjectivity within the Symbolic Order, is maintained, carrying with it significant further connotations for the embodied relations between individual subjects and their changing cultural, social and economic contexts.

\section{Acknowledgements}

To Jenny Parkes and to the editors of this issue, for perceptive comment on early drafts. The research was funded by an ESRC doctoral studentship.

\section{Bibliography}

Appignanesi, L. and Forrester, J. (2005) Freud's Women (Phoenix)

Bernstein, B. (1996) Pedagogy, Symbolic Control and Identity, (Rowman and Littlefield)

Butler, J, 1993, Bodies That Matter (London, Routledge)

Butler, J. (2000) 'Restaging the universal: Hegemony and the limits of formalism', in Butler, J. Laclau, E. and Zizek, S. Contingency, Hegemony and Universality - Contemporary Dialogues on the Left (London, Verso )

Coate, K. (2000) The history of women's studies as an academic subject area in higher education in the UK : 1970-1995, Unpublished PhD thesis, University of London, Institute of Education, London

Dowling, P. (1998) The Sociology of Mathematics Education: Mathematical Myths/Pedagogic Texts. (London, Falmer)

Dowling, P, 2005, 'Treacherous Departures', available online at: http://homepage.mac.com/paulcdowling/ioe/publications (accessed December 2005)

Frosh, S. (1994) Sexual Difference: Masculinity and Psychoanalysis (London and New York, Routledge)

Fuss, D. (1989) Essentially Speaking (London and New York, Routledge)

Irigaray, L (1985) This Sex Which is Not One (Ithaca, New York, Cornell University Press)

Irigaray, L (1993) Sexes and Genealogies (New York: Columbia University Press)

Kristeva, J. (1986a) 'Revolution in Poetic Language', in Moi, T. ed., The Kristeva Reader (Oxford UK and Cambridge USA, Blackwell)

\footnotetext{
${ }^{3}$ For examples of how such marginalisation might be effected, see, for example, some sociological interpretations of what Bernstein calls 'the confessional narratives of a variety of Feminist and Black Studies in higher education' (Bernstein, 1996, p. 170, Maton, 2000, and Moore and Muller, 1999). See also some historical accounts of the development of Women's Studies courses (Coate, 2000 and in this volume, Middleton, 1982)
} 
Kristeva, J. (1986b) 'Psychoanalysis and Polis', in Moi, T. ed., The Kristeva Reader (Oxford UK and Cambridge USA Blackwell)

Lacan, J. (2001) 'The signification of the phallus', in Ecrits: a selection (London and New York, Routledge)

Lacan, J. (1988) On Feminine Sexuality, the Limits of Love and Knowledge, 1972 - 1973 (New York, London, W.W. Norton)

Laclau, E. (2000) 'Structure, History and the Political' in Butler. J, Laclau, E. and Zizek, S. Contingency, Hegemony and Universality - Contemporary Dialogues on the Left (London, Verso)

Lapping, C. (2004) Discipline, Gender and Institution: an empirical study of in/exclusion in undergraduate American Literature and Political Thought classes, Unpublished PhD thesis (University of London, Institute of Education, London)

Lapping, C. (2005) 'Antagonism and Overdetermination: the production of student positions in contrasting undergraduate disciplines and institutions in the UK', in British Journal of Sociology of Education, 26/5, 657 - 671

Maton, K. (2000) 'Languages of Legitimation: the structuring significance for intellectual fields of strategic knowledge claims', in British Journal of Sociology of Education, Vol. 21, No. 2, $147-167$

McNay, L. (2000) Gender and Agency: Reconfiguring the Subject in Feminist and Social Theory (Polity Press)

Middleton, S. (1982) 'Women's studies at Waikato: a case study in the classification and framing of educational knowledge', Delta, 31, 3 - 17

Mirfield, P. (2001) 'Teaching Law, Learning Law: Growing Up Intellectually', in Palfreyman, D, (ed.) The Oxford Tutorial: 'thanks, you taught me how to think' (Oxford Centre for Higher Education Policy Studies)

Moore, R. and Muller, J. (1999) 'The Discourse of 'Voice' and the Problem of Knowledge and Identity in the Sociology of Education', in British Journal of Sociology of Education, 20/2, $189-206$

Ragland Sullivan, E. (1986) Jacques Lacan and the Philosophy of Psychoanalysis (Urbana and Chicago, University of Illinois Press)

Rose, J. (1986) Sexuality in the Field of Vision (London, New York,Verso)

Skeggs, B. (2005) 'The Making of Class and Gender through Visualizing Moral Subject Formation', in British Journal of Sociology of Education, 39/5, 965 - 982

Verhaeghe, P. (1999) Does The Woman Exist? From Freud's Hysteric to Lacan's Feminine (Rebus Press)

Whitford, M. (1991) Luce Irigaray: Philosophy in the Feminine (London and New York, Routledge)

Woolf, V. (1994) A Room of One's Own, (Flamingo)

Zizek, S. (1994) The Metastases of Enjoyment (London, New York, Verso)

Total word count: 8050 